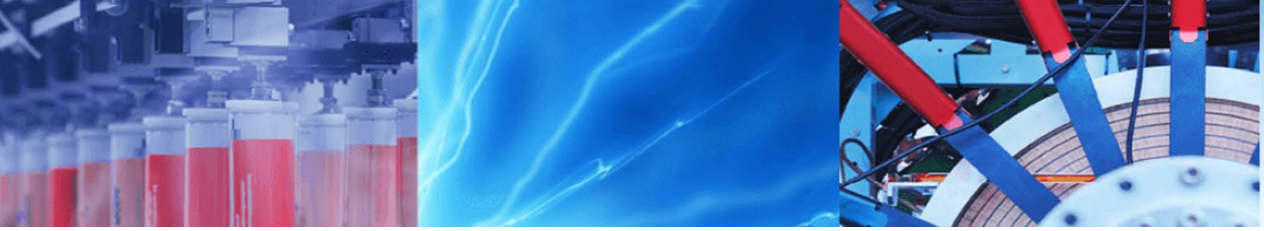

Research Article

\title{
A comparative study of $P \& O$ and INC maximum power point tracking techniques for grid-connected PV systems
}

\author{
Shazly A. Mohamed ${ }^{1} \cdot$ Montaser Abd El Sattar $^{2}$
}

(c) Springer Nature Switzerland AG 2019

\begin{abstract}
The electrical demand is quickly increased, and renewable energy sources are an indispensable need for supporting the electric grid and supplying the isolated loads. Renewable energy is found in numerous forms like solar energy, wind energy, tidal energy. Solar power system is clean, and large amounts of solar radiation arrive to the surface of the earth. This paper aims to maximize the amount of extracted electrical power from the solar energy system. This work investigates in detail the concept of MPPT techniques which significantly increase the efficiency of the solar PV system. This paper presents a simulation-based comparative study between two most common algorithms, perturb and observe and incremental conductance techniques, to optimize the energy conversion efficiency of PV system. Simulation analysis and results of the PV module are made to get its characteristics.
\end{abstract}

Keywords Grid-connected photovoltaic (PV) system · Maximum power point tracking (MPPT) techniques · Power converters

\section{Introduction}

Recently, renewable energy resources like wind turbines, photovoltaic (PV) panels, gas turbines and fuel cells have gained a significant chance as new means of power generation to face the increasing demand for electric energy [1]. Among different kinds of renewable energy resources, solar energy has become one of the most favorable and attractive resources. Nowadays, solar energy-based PV is considered to be one of the most useful natural energy sources, which is widely used in many applications as it has the advantage of easy maintenance, pollution free and most widely distributed [2,3]. Lately, the use of PV panel has grown consistently due to the following factors: enhancement of the PV efficiency and improvement in the industrialization technology. In recent years, a great number of PV modules are inserted into the utility grid in many countries. The use of PV systems has become a current way of power generation due to its environmental credentials, well-known technology, free energy source, little maintenance, increase in efficiency, reduction in costs as well as generation of electricity without moveable parts and a long life span compared to other renewable sources [4]. Solar energy system can be converted immediately into electricity using PV panels through the photovoltaic effect. But the conversion efficiency is low and the cost of power generated is comparatively high. PV generation has many advantages such as it has low fuel costs, does not produce pollution, requires little maintenance, and PV system has more other features [5]. PV applications can be divided into two combinations: stand-alone and grid-connected energy systems. Stand-alone energy systems require a battery bank to store the PV energy; this is suitable for lowpower applications. Moreover, grid-connected PV energy systems do not require battery banks; they are restored usually in high-power applications [6]. PV device is a power

$\triangle$ Shazly A. Mohamed, Eng_shazlyabdo@yahoo.com; Drshazlyabdo@eng.svu.edu.eg; Montaser Abd El Sattar, mymn2013@yahoo.com; Montaser.A.Elsattar@mhiet.edu.eg| 'Department of Electrical Engineering, Faculty of Engineering, South Valley University, Qena, Egypt. ${ }^{2}$ Department of Electrical and Computer Engineering, El-Minia High Institute of Engineering and Technology, El-Minia, Egypt.

SN Applied Sciences (2019) 1:174 | https://doi.org/10.1007/s42452-018-0134-4

Received: 1 August 2018 / Accepted: 17 December 2018 / Published online: 22 January 2019 
system designed to supply applicable power by means of photovoltaic cells. It consists of several components, including solar panels to convert sunlight into electricity, an inverter to change the electric current from DC-AC, as well as mounting, cabling and other electrical parts to set up a working system.

This paper focuses on the grid-connected PV power generation systems which represent the most important field applications of solar energy. The main task of the gridconnected PV system is extracting the maximal quantity possible of solar energy and restoring it to the grid with a unity power factor, despite changing atmospheric conditions like temperature and radiation. Grid-connected PV systems are installed to reinforce the performance of the electrical grid by reducing the power losses, improving the voltage profile and reducing the maintenance/operational costs of the utility grid [7]. In general, the common gridconnected PV systems are consisting of main components such as PV solar cell, power converters and grid interface control system as depicted in Fig. 1. The main task of gridconnected PV system is to control the power flow between the primary renewable energy source and the utility grid, as well as the power factor of PV inverter grid connection with high power quality.

Generally, maximum power point tracking (MPPT) is a technique that is used with PV solar systems to maximize power extraction under any environmental conditions. Several MPPT algorithms have been developed for use in PV systems to reach the MPP, ranging from simple to more complex algorithms depending on the weather conditions and the application [8]. The main task of the MPPT is to extract maximum output power from the PV module under different radiation and temperature conditions. Till now, various MPPT algorithms have been developed in the literature to increase the efficiency of the PV system and to satisfy the optimal MPPT. These algorithms vary in different aspects like tracking speed, cost and hardware required for implementation and application. Generally, most known MPPT methods available are perturb and observe (P\&O), fractional open-circuit voltage (FOCV), fractional short-circuit current (FSCC), incremental conductance (INC), artificial neural networks (ANN), fuzzy logic (FL) and particle swarm optimization (PSO) [9-12].

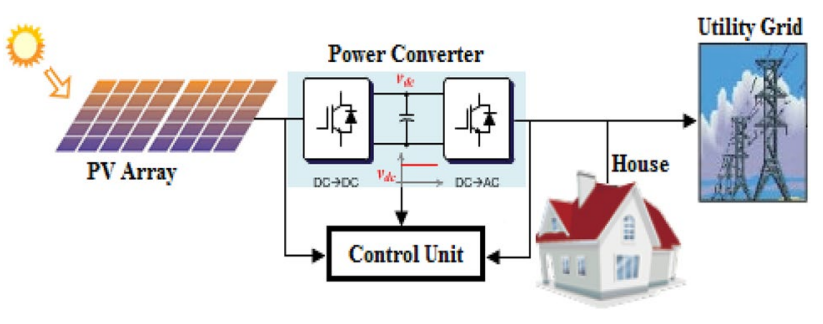

Fig. 1 Configuration of grid-connected PV system
In last few years, artificial intelligence is gaining popularity to track maximum power point (MPP). Artificial neural network (ANN) is one of them. The major advantage of this algorithm is that it does not need to solve the complex mathematical relation between power output, solar irradiance, solar temperature and total resistance plus the outputs are obtained in a very less time with no oscillations at all. The uses of neural network in the industrial electronics have been increased. Recently, its application in various fields is increasing rapidly. The science of artificial neural network depends on the neuron [8].

Among all the above-mentioned algorithms, the perturb and observe (P\&O) and the incremental conductance (INC) are executed and evaluated for MPPT because of their easy implementation, less time to track the MPP and different other economic reasons.

In this study, the performance of solar module at various environmental conditions such as solar temperature and solar irradiance is analyzed. The main contribution of this paper is implementation of the $P \& O$ and incremental conductance (INC) algorithms in MATLAB/Simulink program and, also, determination of which of these two techniques is the most suitable for MPPT to establish an optimal algorithm. The remainder of this paper is organized after Introduction for easy presentation as follows: The conventional PV models are addressed in Sect. 2. Section 3 demonstrates the implementation of different MPPT control algorithms. Simulation results for the proposed model using MATLAB/Simulink program are discussed in Sect. 4. Finally, brief conclusions are drawn in the last section.

\section{PV modeling system}

The basic element of a PV system is the PV cell. A collection of cells connected electrically to form a PV module; several modules form a panel and different panels form a PV array. PV array is composed of various photovoltaic cells in series and parallel connections. Series connections are responsible for increasing the voltage of the system, while the parallel connection is responsible for increasing the current in the module [13]. The power supplied by the PV generator depends on the solar temperature and irradiation intensity. In general, the well-known practical electrical circuit of the solar cell can be modeled by a photo-generated current $\left(I_{\mathrm{ph}}\right)$, a shunt resistor $\left(R_{\mathrm{sh}}\right)$ expressing a leakage current and inserted in parallel with an inverted diode, and a series resistor $\left(R_{s}\right)$ describing the internal losses due to the current flow, as shown in Fig. 2 [14]. The analytical expression model of the output current produced by the solar cell can be expressed as follows $[5,9]$ : 


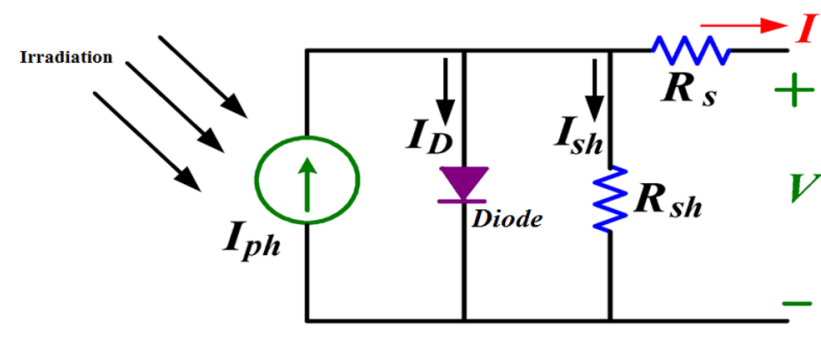

Fig. 2 Practical equivalent circuit of a PV cell

$I=I_{\mathrm{ph}}-I_{\mathrm{D}}-I_{\mathrm{sh}}$

where $I$ is the output current of PV cell $(A), I_{\text {ph }}$ is the photogenerated current $(A), I_{D}$ is the diode current $(A)$ and $I_{\text {sh }}$ is the shunt current $(A)$.

By the Shockley diode equation, the current diverted through the diode can be defined as [5, 9]:

$I_{\mathrm{D}}=I_{\mathrm{o}}\left(\exp \left[\frac{q\left(V+I R_{\mathrm{s}}\right)}{m k T_{\mathrm{c}}}\right]-1\right)$

However, the mathematical expression for the current in a PV cell according to the model is as follows $[5,9]$ :

$I=I_{\mathrm{ph}}-I_{\circ}\left(\exp \left[\frac{q\left(V+I R_{\mathrm{s}}\right)}{m k T_{\mathrm{c}}}\right]-1\right)-\left(V+I R_{\mathrm{s}}\right) / R_{\mathrm{sh}}$

where $I_{0}$ is the diode saturation current $(A), q$ is the elementary charge $\left(1.6 \times 10^{-19} \mathrm{C}\right), K$ is the Boltzmann gas constant $\left(1.38 \times 10^{-23} \mathrm{~J} / \mathrm{K}\right), m$ is the diode quality factor, $V$ is the $\mathrm{PV}$ cell output voltage, $T_{\mathrm{c}}$ is the absolute temperature of the cell $(\mathrm{K}), R_{\mathrm{s}}$ is the series resistance of the cell $(\Omega)$ and $R_{\mathrm{sh}}$ is the shunt resistance of the cell $(\Omega)$.

The two most prevalent models of PV modules are the single-diode and the double-diode models. In order to design a model of the solar panel accurately, we can use double-diode model. In this paper, the single-diode model is used because of its simplicity and accuracy.

The current at maximum power point $\left(I_{\mathrm{mp}}\right)$ can be expressed as follows:

$I_{\mathrm{mp}}=I_{\mathrm{ph}}-I_{\mathrm{o}}\left(\exp \left[\frac{q\left(V_{\mathrm{mp}}+I_{\mathrm{mp}} R_{\mathrm{s}}\right)}{m k T_{\mathrm{c}}}\right]-1\right)-\left(V_{\mathrm{mp}}+I_{\mathrm{mp}} R_{\mathrm{s}}\right) / R_{\mathrm{sh}}$.

However, the power at maximum power point $\left(P_{\max }\right)$ is given by:

$P_{\max }=V_{\mathrm{mp}}\left\{I_{\mathrm{ph}}-I_{\mathrm{o}}\left(\exp \left[\frac{q\left(V_{\mathrm{mp}}+I_{\mathrm{mp}} R_{\mathrm{s}}\right)}{m k T_{\mathrm{c}}}\right]-1\right)-\left(V_{\mathrm{mp}}+I_{\mathrm{mp}} R_{\mathrm{s}}\right) / R_{\mathrm{sh}}\right\}$, where $I_{m p}$ is the maximum panel current and $V_{m p}$ is the maximum panel voltage.

\section{MPPT implementation control techniques}

There is a unique point on the curve at which the PV power is maximum (MPP). The power corresponding to this point is defined as cell power at maximum $\left(P_{\mathrm{MPP}}\right)$, and the voltage is defined as cell voltage at maximum $\left(V_{M P P}\right)$. The need for MPPT is the power output of the solar PV system varies with irradiation level and cell temperature. The main rule of MPPT is to extract the maximum available energy from PV device by making them operate at the most efficient voltage $[15,16]$. Figure 3 illustrates the characteristics of a common PV cell at standard test conditions which mainly depend on the irradiance and the cell temperature. From this curve, it is noticed that the magnitude of $V_{\text {MPP }}$ is lower than the magnitude of $V_{\mathrm{OC}}$ and the magnitude of $I_{\mathrm{MPP}}$ is lower than the magnitude of $I_{\mathrm{SC}}$.

When the irradiance is changed from $400,600,800$ and $1000 \mathrm{~W} / \mathrm{m}^{2}$ under constant cell temperature, it is obvious that the PV current and voltage will increase with irradiance levels and PV array output power also increases. The response of solar irradiance with constant temperature is depicted in Fig. 4. On the other hand, when the cell temperature varies from $25^{\circ} \mathrm{C}, 50^{\circ} \mathrm{C}$ and $75^{\circ} \mathrm{C}$ at constant solar irradiation intensity, the PV current will increase marginally with drastic decrease in PV array voltage and PV array output power is reduced. The response of solar cell temperature with constant irradiance intensity is illustrated in Fig. 5.

In general, the MPPT is an electronic device inserted between the PV generator and its load. It aims to keep the working point of the system as close to the MPP. The MPPT has nonlinear characteristic of solar PV module. It has one maximum power point which depends on irradiation intensity and cell temperature. However, it is requisite to track continuously the MPP to maximize the output power from a PV device [17]. The efficiency of a solar panel is very low. In order to improve the efficiency of the solar panel, MPPT is used. There are different algorithms that are used to control the MPPT. The algorithms that are most commonly used are the $\mathrm{P} \& \mathrm{O}$ and INC methods which are presented in this study.

\footnotetext{
is

is
} 


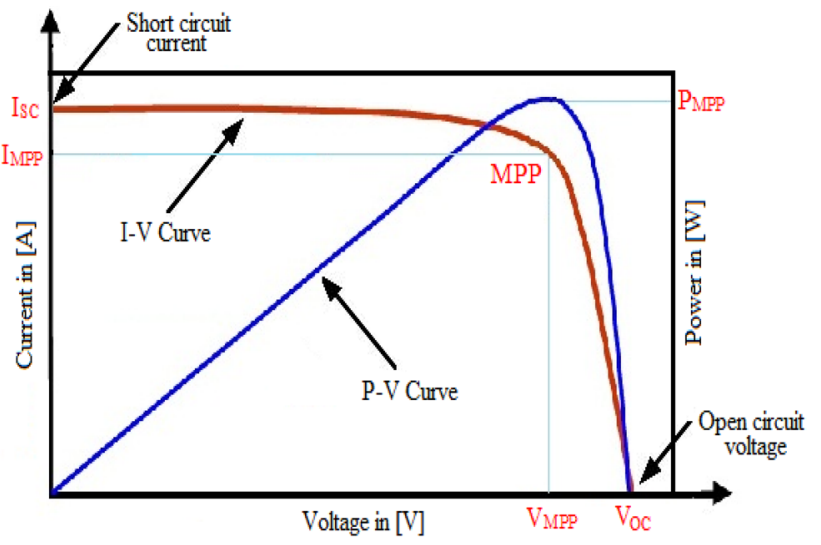

Fig. 3 Typical characteristic of a common PV cell

\subsection{P\&O MPPT algorithm}

The perturb and observe $(\mathrm{P} \& \mathrm{O})$ algorithm is generally the most commonly applied in the control of MPPT algorithm for the PV generator. It has simple structure, low cost, easy to implement, reduced number of parameters, the possibility to introduce improvements and may result in top-level efficiency [18-20]. This algorithm is depending on investigating the relation between PV module output power and its voltage. The behavior of solar panel indicating MPP and operating principle is shown in Fig. 6 which indicates that the resulting change of PV power is observed as follows: When the PV module operating point is on the left side of the curve ( $\triangle P I \Delta V$ is positive), which means the PV module output power increases, the perturbation of the PV module voltage should be increased
Fig. 4 Response of solar irradiance with constant temperature

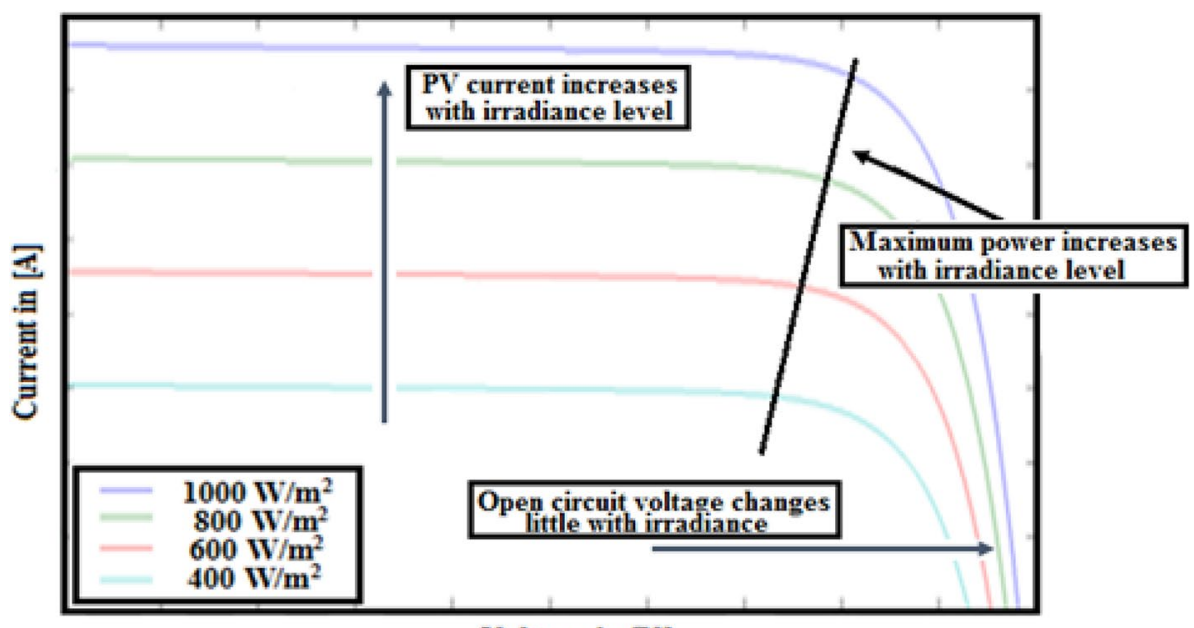

Voltage in [V]

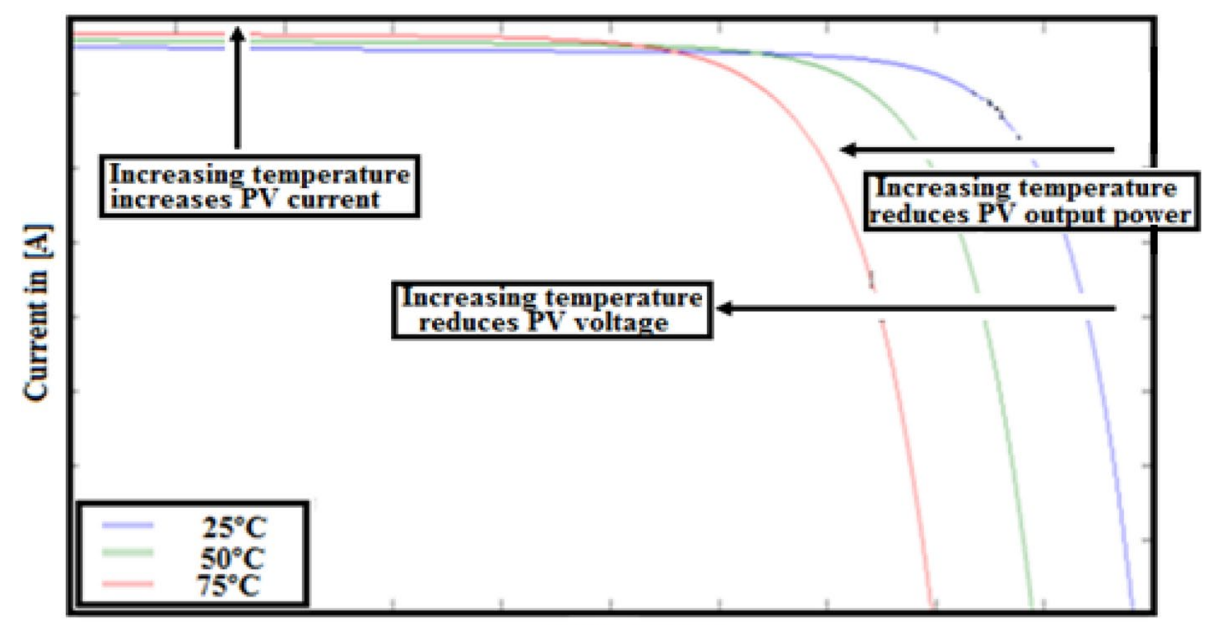

Voltage in [V] 


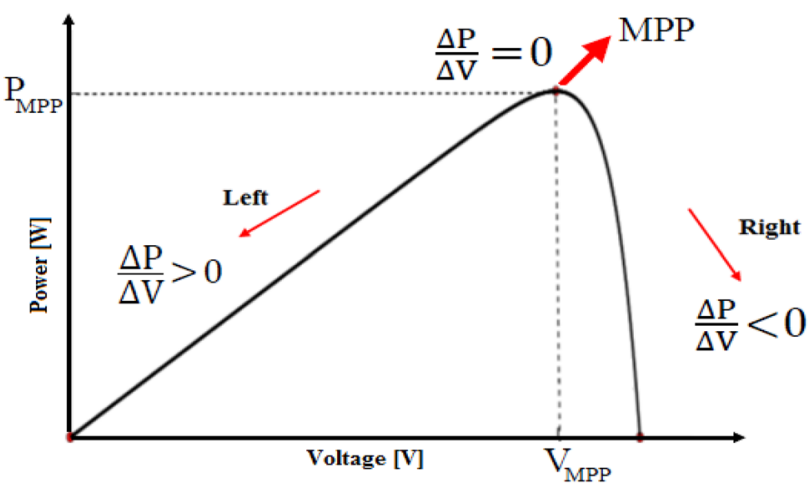

Fig. 6 Behavior of solar panel indicating MPP and operating principle

toward the MPP. If the operating point of the module was on the right side of the curve ( $\triangle P I \Delta V$ is negative), then the perturbation of the PV module voltage should be decreased toward the MPP.

Fig. 7 Flowchart of the $\mathrm{P} \& \mathrm{O}$ algorithm
Figure 7 depicts the flowchart for implementation of the $\mathrm{P} \& \mathrm{O}$ algorithm; first, the practical voltage and current from PV array are measured. After that, the product of voltage and current gives the actual power of PV module. Then, it will check status what whether $\triangle P=0$ or not. If this status is satisfied, then operating point is at the MPP. If it is not satisfying, then it will check another status that $\Delta P>$ 0 . If this status is satisfied, then it will check out that $\Delta V>$ 0 . If it is satisfied, then it indicates that operating point is at the left side of the MPP. If $\Delta V>0$ status is not satisfied, then it indicates that operating point is at the right side of the MPP. This process is continuously repeated until it reached the MPP. So, at all times there is a compromise between the increments and the sampling rate in the $P \& O$ algorithm.

\subsection{INC MPPT algorithm}

In incremental conductance (INC) algorithm, the controller measures incremental changes in PV array voltage and current to predict the effect of a voltage change. This method

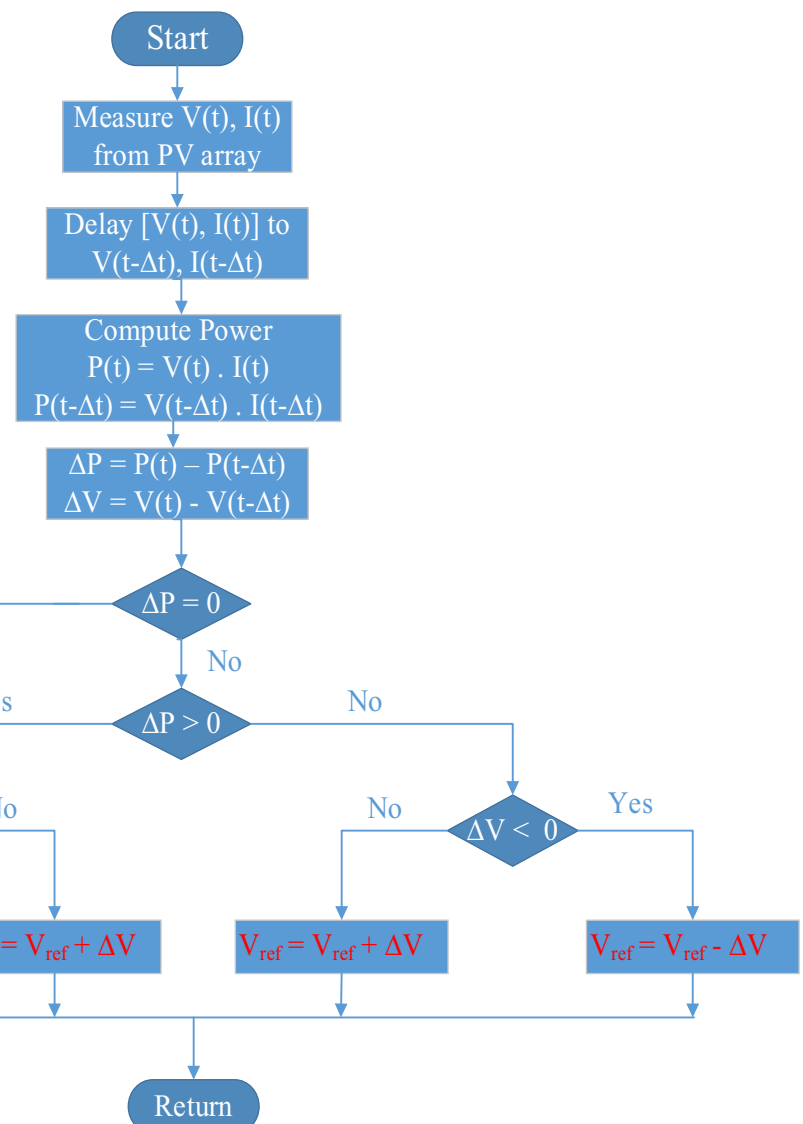


requires more computation in the controller, but can track changing conditions more quickly than the $\mathrm{P} \& \mathrm{O}$ algorithm $[21,22]$. Like the $P \& O$ algorithm, it can produce oscillations in output power. This technique utilizes the incremental conductance $(\Delta / / \Delta V)$ of the PV array to calculate the sign of the variation in power with respect to voltage $(\triangle P I \Delta V)$. The INC algorithm calculates the maximum power point by comparison of the incremental conductance $(\Delta / / \Delta V)$ with the array conductance $(I / V)$. When these two are the same $(\Delta / / \Delta V=I / M)$, the output voltage is the MPP voltage. The controller maintains this voltage until the irradiation changes and the process is repeated. The INC algorithm is based on the fact that at the maximum power point $\Delta P I \Delta V=0$ and $P=V I$. Incremental conductance algorithm has only two sensors, voltage and current sensors, which are required in order to measure the PV device output voltage and current [23]. The flowchart for implementation of the INC algorithm is depicted in Fig. 8. The corresponding equation that mathematically describes the INC algorithm can be expressed as follows: The output power from the source can be written as follows:

$P=V \cdot I$.
The fact that $P=V \cdot I$ and the chain rule for the derivative of products with respect to voltage yield:

$$
\begin{aligned}
\Delta P & / \Delta V=\Delta(V I) / \Delta V \\
& =I \Delta V / \Delta V+V \Delta l / \Delta V \\
& =I+V \Delta l / \Delta V
\end{aligned}
$$

$$
(1 / V) \Delta P / \Delta V=(I / V)+\Delta l / \Delta V
$$

Ordinarily, the output voltage from a source is positive. The main task of this algorithm is therefore to search the voltage operating point at which the conductance is equal to the incremental conductance. These concepts are expressed by Eqs. (8-10) and graphically depicted in Fig. 6. The INC algorithm depends on the slope of the $P-V$ curve. The slope will become zero at MPP, increases (positive) on the left side of the MPP and decreases (negative) on the right side of the MPP. The basic equations of this algorithm are as follows:

$\Delta P / \Delta V>0$, Left side of the MPP

$\Delta P / \Delta V=0, \quad$ at the MPP
Fig. 8 Flowchart of the INC algorithm

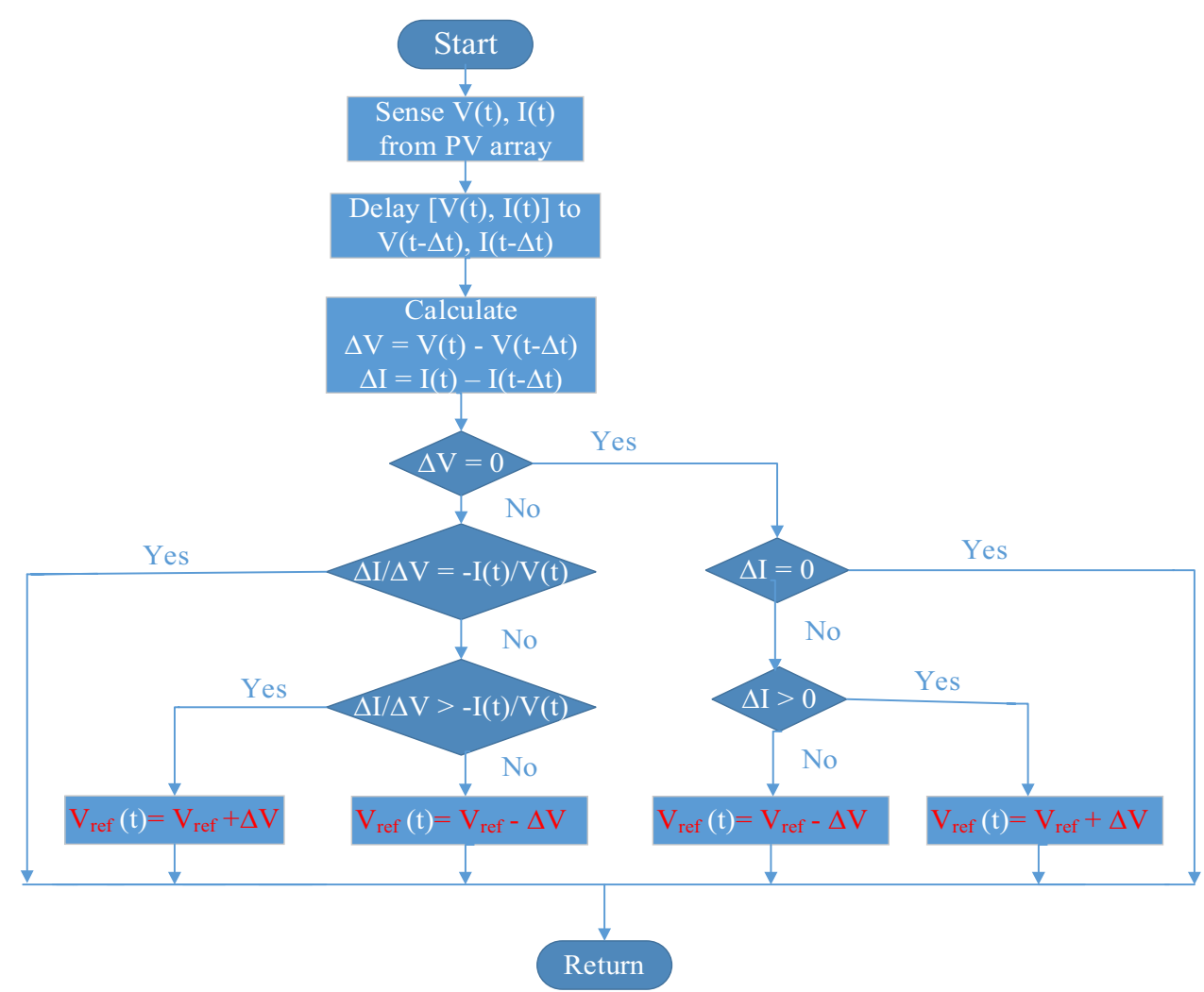


$\Delta P / \Delta V<0, \quad$ Right side of the MPP.

The slope ( $\triangle P I \Delta V$ ) can be calculated using the PV module output voltage and current. The incremental conductance algorithm is derived by differentiating the PV module output power with respect to voltage and setting the result equal to zero. Therefore, the relation between the instantaneous conductance (I/V) and the incremental conductance $(\Delta / / \Delta V)$ can be calculated based on Eq. (7) as follows [9]:

$\frac{\Delta l}{\Delta V}=-\frac{l}{V} \quad$ at the MPP

$\frac{\Delta l}{\Delta V} \geq-\frac{l}{V} \quad$ Left side of the MPP

$\frac{\Delta l}{\Delta V} \leq-\frac{I}{V}$ Right side of the MPP.

The PV generator output is required to contain a DC-DC converter to set the solar modules output voltage at the desired value in order to track the MPP. The power converters are the devices widely used in many industrial applications. The three topologies which are more popular are the buck, boost and buck-boost power converters. These topologies have several properties depending on the connection between their devices. In this paper, the boost converter topology is used because its free-wheeling diode can be used for blocking reverse current and it efficiently amplifies PV array output voltage to higher value and is controlled by pulse width modulation (PWM) switch.

Boost power converter topology steps up the input voltage magnitude to a required output voltage magnitude without the use of a transformer [24]. The basic components of a boost converter are an inductor, a capacitor, a diode and a high-frequency switch as illustrated in Fig. 9.

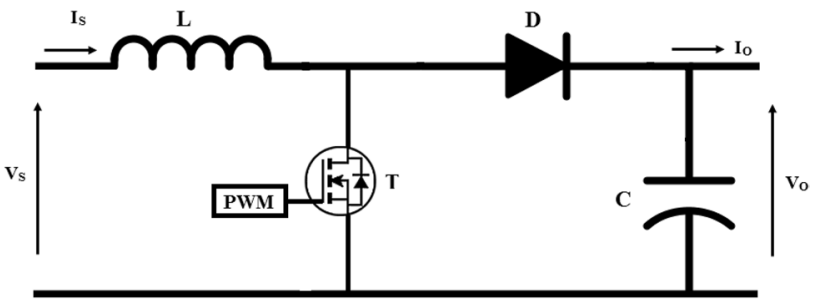

Fig. 9 Simplified circuit of boost converter topology
The parameters used are $I_{s^{\prime}}$ the input current, $V_{s^{\prime}}$ the input voltage, $I_{\mathrm{o}}$, the output current, and $V_{\mathrm{o}^{\prime}}$, the output voltage. For steady-state operation, the average voltage through the inductor over a full period is zero. The relationship between the input and output voltages conversion ratio can be expressed as follows:

$V_{\mathrm{s}} \times T_{\text {on }}-\left(V_{\mathrm{o}}-V_{\mathrm{s}}\right) T_{\text {off }}=0.0$.

Therefore,

$V_{\mathrm{s}} \times \alpha \times T=\left(V_{\mathrm{o}}-V_{\mathrm{s}}\right)(1-\alpha) T$,

where $a=T_{\text {on }} / T$ is the duty cycle $(0<a<1) . T=T_{\text {on }}+T_{\text {off }}$ is the switching period.

$\frac{V_{\mathrm{o}}}{V_{\mathrm{s}}}=\frac{T_{\text {on }}+T_{\text {off }}}{T_{\text {off }}}=\frac{1}{1-\alpha}$.

The output voltage is quite sensitive to changes in duty cycle (a). So, the average output current is less than the average inductor current by a factor of $(1-a)$, and a much higher rms current would flow through the filter capacitor. Usually, the DC-AC converter, which is well known as the inverter as depicted in Fig. 10, mainly converts DC-AC power at desired output voltage and frequency. The DC power input to the inverter is obtained from an existing power grid or from a rotating alternator through PV array, battery, rectifier or fuel cell. The filter capacitor across the input terminals of the inverter provides a constant DC link voltage. Therefore, the inverter is an adjustable-frequency voltage source [25].

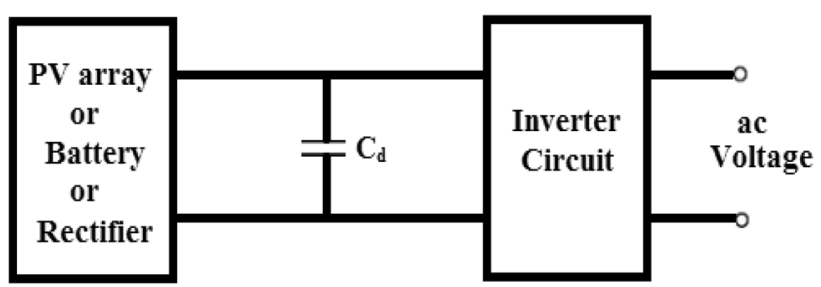

Fig. 10 Schematic diagram of DC-AC converter model 


\section{Simulation analysis, results and discussion}

In the present simulation model, the PV panel is connected with grid system as depicted in Fig. 11. The designed PV system aims to transfer electrical power from PV array to the utility grid. Simulation analysis and results are obtained using MATLAB/Simulink program for the MPPT control algorithms. The modeling system is used to highlight the difference between two P\&O and the INC algorithms which are used in this paper.

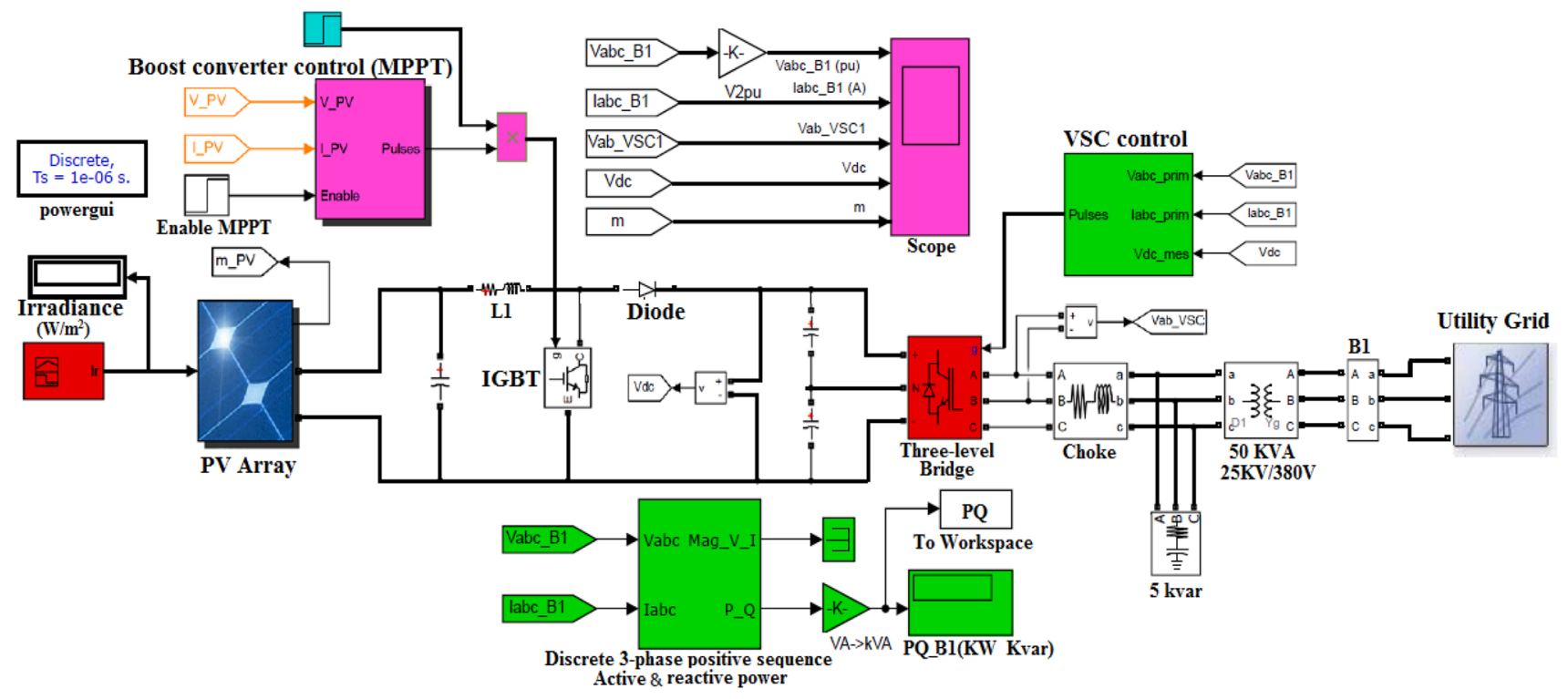

Fig. 11 Detailed simulation circuit of grid-connected PV model 


\subsection{Results of PV side for $P \& 0$ algorithm}

Figure 12 shows the simulation results of the $P \& O$ method at PV side. It indicates that the irradiance profile with time is applied to the PV module, current and voltage characteristics of the PV module and the PV module output active power, respectively.
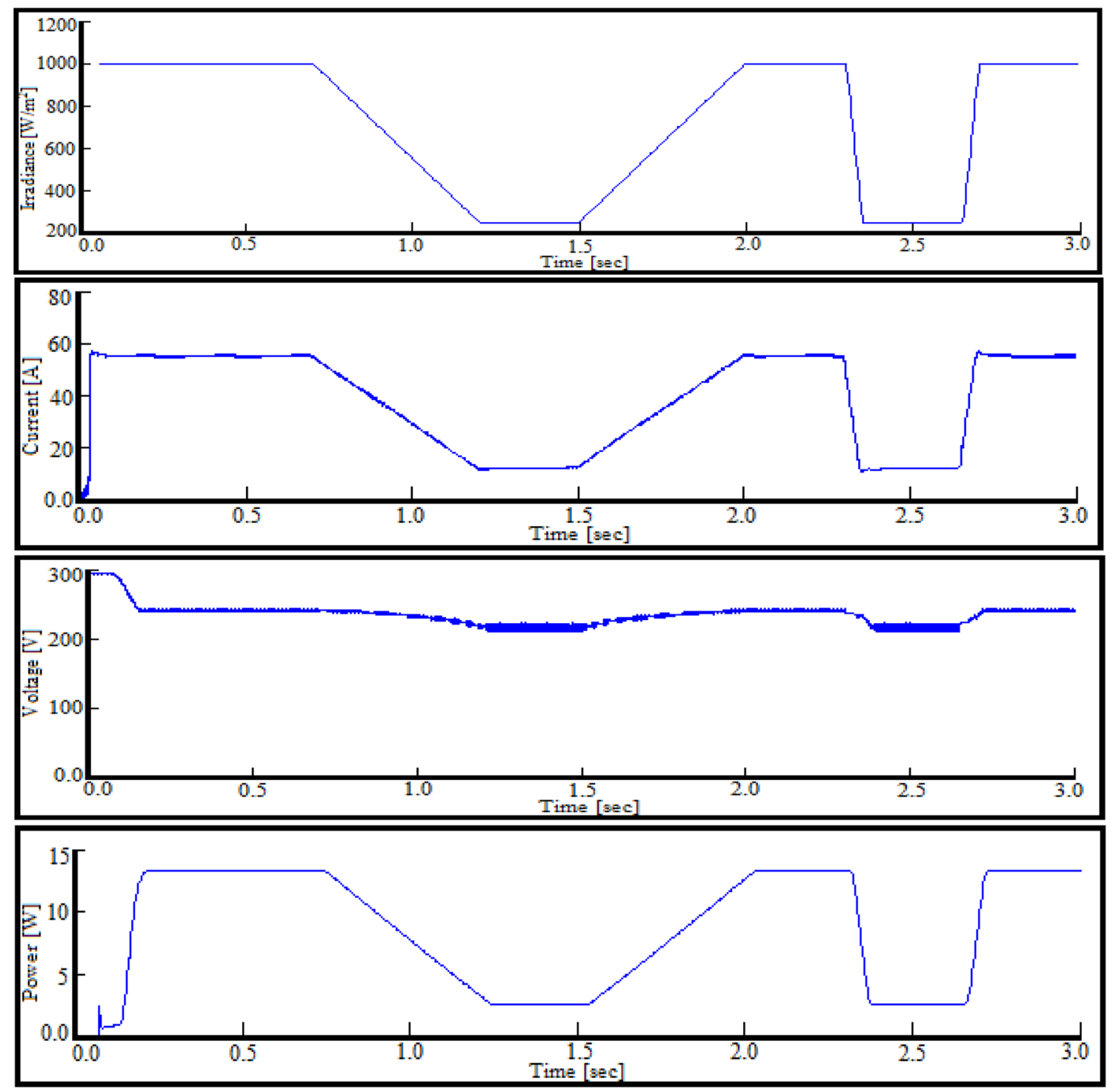

Fig. 12 Simulation results of $\mathrm{PV}$ side with $\mathrm{P} \& \mathrm{O}$ technique 


\subsection{Results of grid side for $P \& 0$ algorithm}

Figure 13 shows the simulation results of the $P \& O$ method at grid side. It indicates that the $d$-axis current reference on the grid side, the $q$-axis current reference, changes in active and reactive power on the grid side, DC voltage input to the inverter and, finally, voltage and current injected to the utility grid from the PV system at the connection point are in phase, respectively.
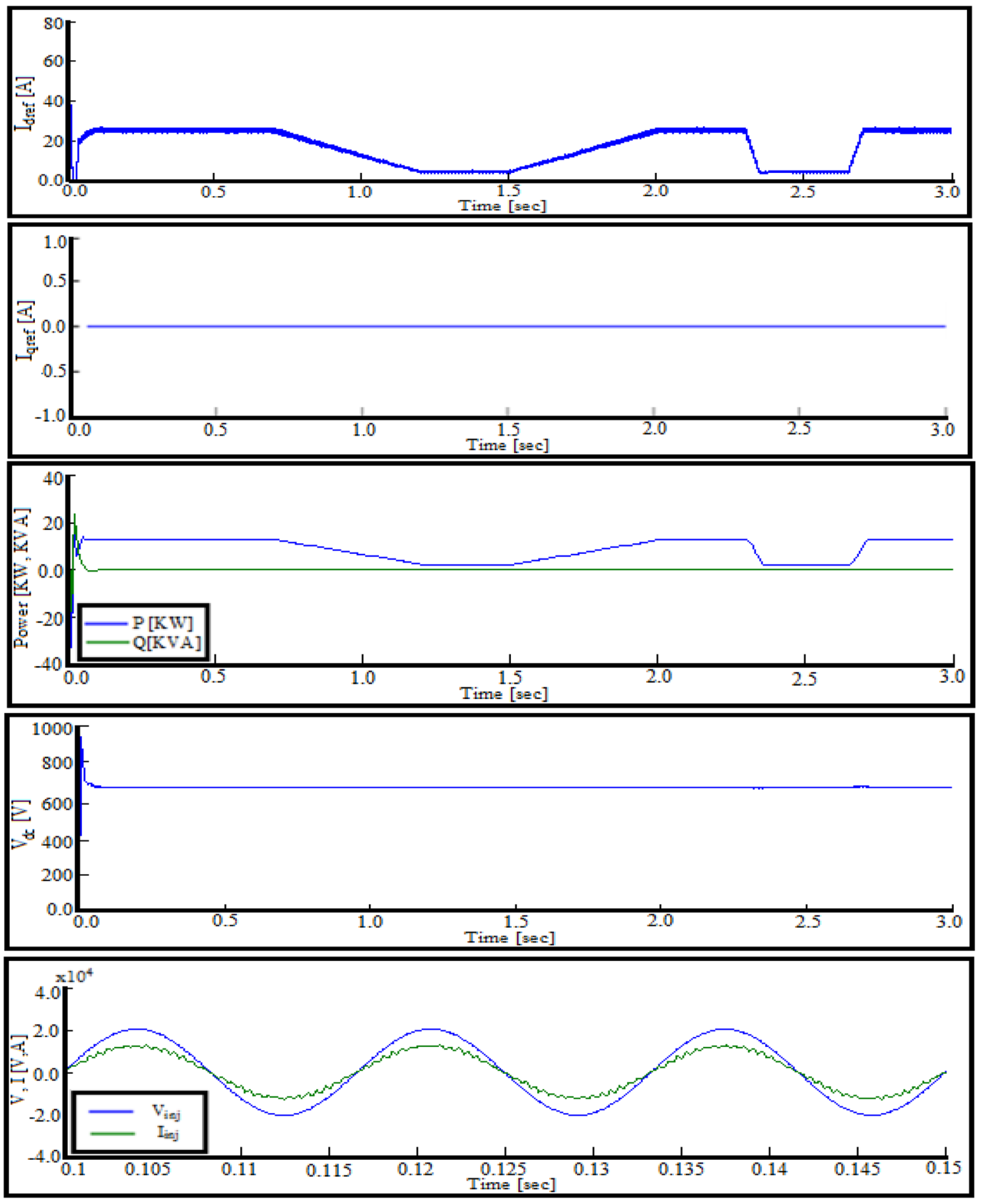

Fig. 13 Simulation results of grid side with $P \& O$ technique 


\subsection{Results of PV side for INC algorithm}

Figure 14 illustrates the simulation results of the incremental conductance method at PV side. It indicates that the irradiance profile with time is applied to the PV module, current and voltage characteristics of the PV module and the PV module output active power, respectively.
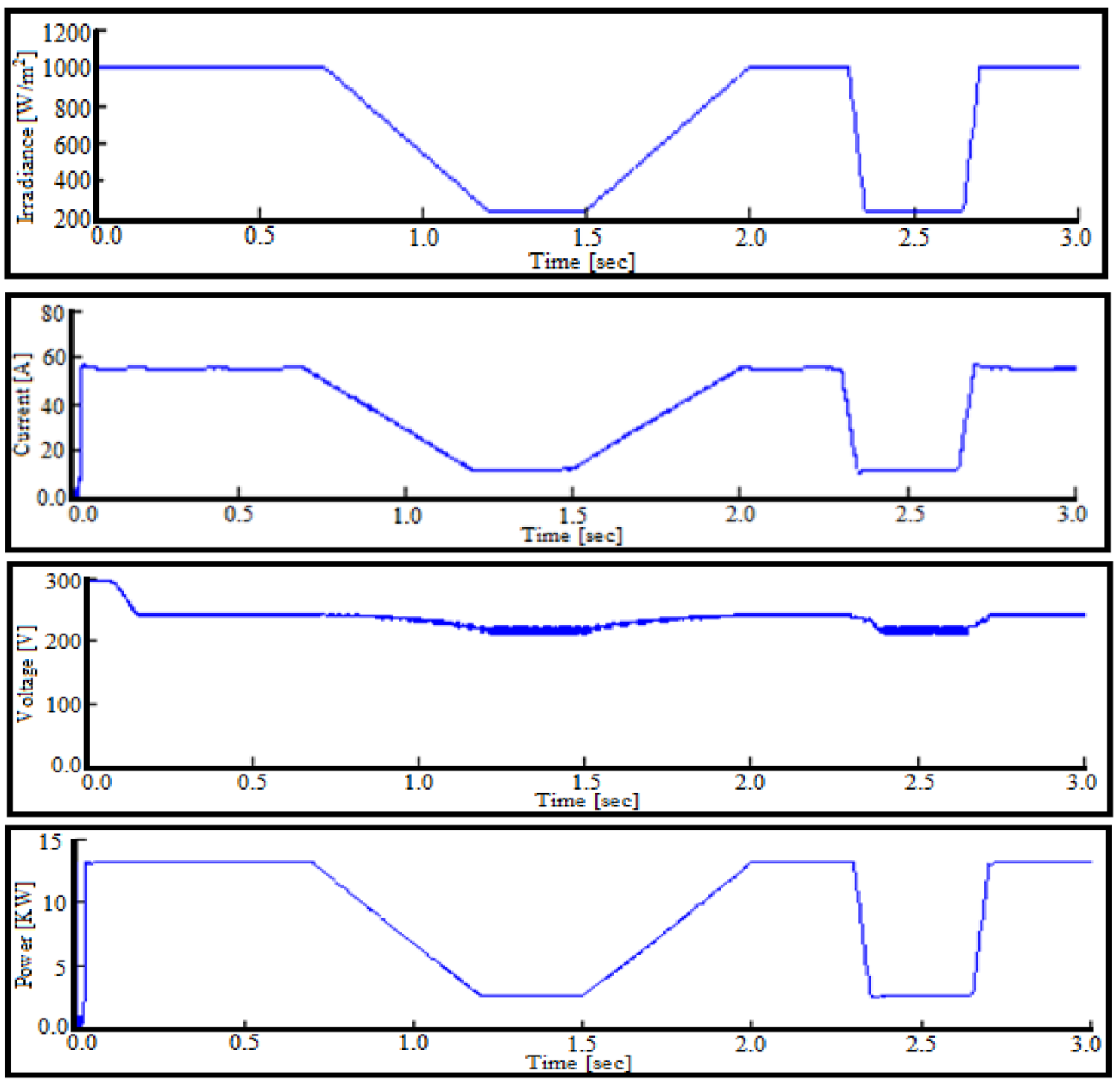

Fig. 14 Simulation results of PV side with INC technique 


\subsection{Results of grid side for INC algorithm}

Figure 15 illustrates the simulation results of the INC method at grid side. It indicates that the $d$-axis current reference on the grid side, the $q$-axis current reference, changes in active and reactive power on the grid side, DC voltage input to the inverter and, finally, the voltage and current injected to utility grid from the PV system at the connection point are in phase, respectively.
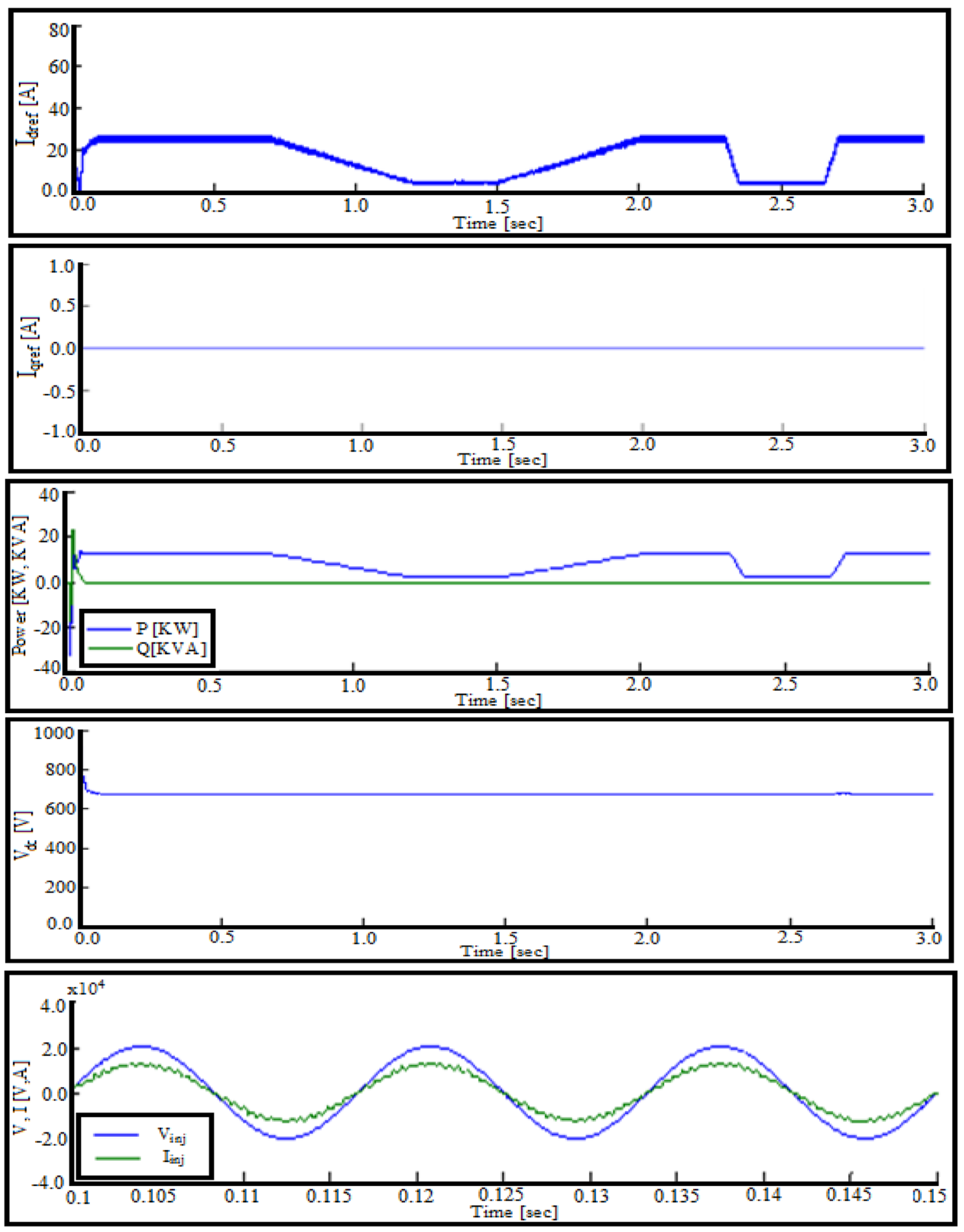

Fig. 15 Simulation results of grid side with INC technique 


\section{Conclusion}

This paper presents a grid-connected PV system at low distribution voltage, suitable for residential, industrial and small customer applications. Also, the MPPT techniques are implemented using incremental conductance (INC) and perturb and observe (P\&O) with boost converter topology. Simulation results with MATLAB/Simulink program show the PV side and grid side performance with time and irradiance variation. INC algorithm tracks rapidly changing irradiation conditions more accurately than $\mathrm{P} \& \mathrm{O}$ method. In $\mathrm{P} \& \mathrm{O}$ method, the voltage never actually reaches an exact value but perturbs around the MPP. So, the INC method reaches the MPP faster and better than P\&O because of not have drifting problem and it was the most efficient, at rapidly changing conditions.

\section{Compliance with ethical standards}

Conflict of interest The authors declare that they have no competing interests.

\section{References}

1. Vidhya K, Ghani A, Zhou E (2016) Modelling and simulation of maximum power point tracking algorithms and review of MPPT techniques for PV applications. In: 5th international conference on electronic devices, systems and applications (ICEDSA), 6-8 Dec 2016 pp 1-4

2. Huynh D, Dunnigan M (2015) Maximum power point tracking using an adaptive perturbation and observation algorithm for a grid-connected solar photovoltaic system. Int J Grid Distrib Comput 8(3):97-110

3. Arulkumar K, Palanisamy K, Vijayakumar D (2016) Recent advances and control techniques in grid connected PV system-a review. Int J Renew Energy Res 6(3):1028-1049

4. Xiao W, Edwin F, Spagnuolo G, Jatskevich J (2013) Efficient approaches for modeling and simulating photovoltaic power systems. IEEE J Photovolt 3(1):500-508

5. Tanvir A, Sharmin S, Faysal N (2016) Comparative analysis between single diode and double diode model of PV cell: concentrate different parameters effect on its efficiency. J Power Energy Eng 4:31-46

6. Yang B, Li W, Zhao Y, He X (2010) Design and analysis of a grid-connected photovoltaic power system. IEEE Trans Power Electron 25(4):992-1000

7. Pires V, Husev O, Vinnikov D, Martins JF (2015) A control strategy for a grid-connected PV system with unbalanced loads compensation. In: IEEE 9th international conference on compatibility and power electronics (CPE). pp 154-159

8. Ahmed AS, Berzoy A, Mohammed O (2017) Design and hardware implementation of FL-MPPT control of PV systems based on GA and small-signal analysis. IEEE Trans Sustain Energy 8(1):279-290
9. Vidhya K, Arfan G, Erping Z (2016) Modelling and simulation of maximum power point tracking algorithms and review of MPPT techniques for PV applications. In: 5th international conference on electronic devices, systems and applications (ICEDSA), 6-8 Dec 2016, pp 1-4

10. Nandurkar SR et al (2014) Modeling simulation \& design of photovoltaic array with MPPT control techniques. Int J Appl Power Eng (IJAPE) 3(1):41-50

11. Babaa SE et al (2014) Overview of maximum power point tracking control methods for PV systems. J Power Energy Eng 2:59-72

12. Faranda R, Leva S (2008) Energy comparison of MPPT techniques for PV systems. WSEAS Trans Power Syst 3(6):446-455

13. Makhlouf M, Messai F, Nabti K, Benalla H (2012) Modeling and simulation of grid-connected photovoltaic distributed generation system. In: 1st international conference on renewable energies \& vehicular technology, 26-28 Mar 2012, pp 187-193

14. Rakesh R, Kannan S, Jomy J, Kamala D, Jayaraju M (2014) Modelling and analysis of MPPT techniques for grid connected PV systems. Int J Innov Res Electr Electron Control Eng 2(2):1031-1037

15. Bakkar M, Abdel-Geliel M, Zied MA (2015) Photovoltaic Maximum power point grid connected based on power conditioning technique employing fuzzy controller. Renew Energy Power Qual J (RE\&PQJ) 1(13):339-344

16. Hairul N, Saad M (2010) Comparison study of maximum power point tracker techniques for PV systems. In: Proceedings of the 14th international middle east power systems conference (MEPCON'10), Cairo University, Egypt, December 19-21, 2010

17. Attou A, Massoum A, Saidi M (2014) Photovoltaic power control using MPPT and boost converter. Balkan Journal of Electrical \& Computer Engineering 2(1):23-27

18. Elgendy M, Zahawi B, Atkinson D (2012) Assessment of perturb and observe MPPT algorithm implementation techniques for PV pumping applications. IEEE Trans Sustain Energy 3(1):21-33

19. Sahnoun MA et al (2013) Maximum power point tracking using P\&O control optimized by a neural network approach: a good compromise between accuracy and complexity. Energy Procedia 42:650-659

20. Patel G, Patel DB, Paghdal KM (2016) Analysis of P\&O MPPT algorithm for PV system. Int J Electr Electron Eng (IJEEE) 5(6):1-10

21. El-Sayed M, Leeb S (2014) Evaluation of maximum power point tracking algorithms for photovoltaic electricity generation in Kuwait. Renew Energy Power Qual J (RE\&PQJ) 1(12):44-50

22. Lamnad M et al (2016) Comparative study of IC, P\&O and FLC method of MPPT algorithm for grid connected PV module. J Theor Appl Inf Technol 89(1):242-253

23. Tofoli FL, Pereira DC, Paula WJ (2015) Comparative study of maximum power point tracking techniques for photovoltaic systems. Int J Photo-energy 3:1-10

24. Haripriya T, Alivelu M, Rao UM (2016) Performance evaluation of DC grid connected solar PV system for hybrid control of DC-DC boost converter. In: 10th international conference on intelligent systems and control (ISCO), 7-8 Jan 2016, pp 1-6

25. Ozcelik MA, Yilmaz AS (2016) Effect of improving perturb and observe MPPT algorithm on AC grid connected PV systems. IUJEEE 16(2):3025-3032 